ISSN 0103-5150

Fisioter. Mov., Curitiba, v. 30, n. 3, p. 463-471, Jul./Sep. 2017

Licenciado sob uma Licença Creative Commons

DOI: http://dx.doi.org/10.1590/1980-5918.030.003.A004

\title{
Test timed up and go and its correlation with age and functional exercise capacity in asymptomatic women
}

Teste "Timed up and go" e sua correlação com a idade e
capacidade funcional de exercício em mulheres assintomáticas

\author{
Wesley de Oliveira Vieira ${ }^{[a, b]}$, Thatiane Lopes Valentim di Paschoale Ostolin ${ }^{[a, b]}$, Mateus Ferreira ${ }^{[a]}$, \\ Evandro Fornias Sperandio ${ }^{[a, b]}$, Victor Zuniga Dourado ${ }^{[a, b]^{*}}$
}

[a] Universidade Federal de São Paulo (UNIFESP), Santos, SP, Brazil

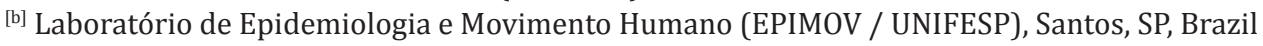

\footnotetext{
WOV: BS, e-mail: personal.woliveira@gmail.com TLVPO: Master Student, e-mail: thati.ostolin@gmail.com

MF: BS, e-mail: ferreira.mateus@live.com

EFS: PhD, e-mail: evandrosperandio@yahoo.com

VZD: PhD, e-mail:vzdourado@yahoo.com.br
}

Introduction: The Timed Up and Go test (TUG) is widely used and valid in chronic patients, but rarely addressed in asymptomatic individuals. Objective: To assess the reliability, the age-related changes and the correlation between TUG and the Functional Exercise Capacity (FEC) adjusted for non-institutionalized middle-aged and elderly women. Methods: Ninety-eight women (57 \pm 10 years) were selected and stratified into age groups. We have performed the tests TUG, Berg Balance Scale (BBS) and evaluation of usual gait speed (UGS). Fifty-eight participants (57 \pm 10 years) also performed incremental shuttle walk test (ISWT). Results: Worse performance in TUG $(p<0,05)$ for participants aged $\geq 70$ years for age groups $40-49$ and 50-59 years. The reliability of TUG was excellent between the first and second TUG (intraclass correlation coefficient, 0.933 ; confidence interval of $95 \%$, from 0.901 to 0.955 ) and between the second and third TUG $(0.958,0.938$ to 0.972$)$. The group of 58 participants who underwent further the ISWT, TUG correlated significantly $(\mathrm{p}<0.05)$ with ISWT $(\mathrm{r}=-0.72)$, VUM $(\mathrm{r}=-0.54)$ and BBS $(\mathrm{r}=0.58)$. A multiple linear regression analysis selected TUG $\left(R^{2}=0.517\right)$ and VUM $\left(R^{2}=0.083\right)$ as determinants of FEC. Conclusion: TUG adapted 
for asymptomatic women is reliable and able to assess the decline of physical mobility with advancing age and it also crucial to the FEC.

Keywords: Gait. Exercise. Postural Balance.

\section{Resumo}

Introdução: Amplamente utilizado, o teste Timed up and Go (TUG) é válido para doentes crônicos, porém pouco abordado em indivíduos assintomáticos. Objetivo: Avaliar a confiabilidade do TUG modificado na deteç̧ão do declínio da mobilidade física com o avanço da idade em mulheres de meia idade e idosas não institucionalizadas e sua correlação com a capacidade funcional de exercício (CFE). Metodologia: Noventa e oito mulheres (57 \pm 10 anos) foram selecionadas e estratificadas em grupos etários. Realizamos os testes TUG, escala de equilíbrio de Berg (EEB) e avaliação da velocidade usual da marcha (VUM). Cinquenta e oito participantes (57 \pm 10 anos) realizaram também o Teste de Caminhada com Carga Progressiva (TCCP). Resultados: Pior desempenho no TUG $(p<0,05)$ para as participantes com idade $\geq 70$ anos em relação aos grupos etários 40-49 e 50-59 anos. A confiabilidade foi excelente entre o $1^{\circ}$ e o $2^{\circ}$ TUG (coeficiente de correlação intraclasse, 0,933; intervalo de confiança de $95 \%, 0,901-0,955)$ e entre o $2^{\circ}$ e o $3^{\circ}(0,958 ; 0,938-0,972)$. No subgrupo que realizou ISWT, o TUG correlacionou-se significativamente $(p<0,05)$ com o TCCP $(r=-0,72)$, a VUM $(r=-0,54)$ e a EEB $(r=-0,58)$. A análise de regressão selecionou o TUG $\left(R^{2}=0,517\right)$ e a VUM $\left(R^{2}=0,083\right)$ como determinantes para a CFE. Conclusão: o TUG adaptado para mulheres assintomáticas é confiável e capaz de avaliar o declínio da mobilidade física com o avanço da idade, sendo também determinante para a CFE.

Palavras-chave: Marcha. Exercício. Equilíbrio Postural.

\section{Introduction}

In clinical practice, the use of field tests is a quick and inexpensive alternative to evaluate the functionality and mobility trunk and lower limbs in performing daily activities, such as walking $(1-6)$, and support the adoption of measures and preventive strategies in attention to health care $(2,7)$.

Regarding field walking tests (3), Timed up and go (TUG) test is a simple operational tool and features associated with a higher gait speed, balance, functional index, overall health decline, inability to activities of daily living and falls $(8-10)$.

It is suggested that there is a consistent correlation between TUG and another index from of balance, for example, the distance covered in the incremental shuttle walk test (ISWT) and performance on Berg Balance Scale (BBS) in adult individuals and asymptomatic elderly (3). This is due to the incremental nature of ISWT, which demands agility to execute the changes of direction, as well the association already established between performance on tests of walking and balance $(3,11)$. Individuals with a history of falls have lower performance, compared to people who did not fall (11).

TUG is widely used and valid in the evaluation of patients with chronic diseases (2). However, its measurements properties were little addressed in asymptomatic individuals. Evaluate the capacity of TUG to assess such individuals can be critical to determine the role of this test in the early detection of changes due to aging, which is usually indentified later, for example, through muscle function evaluations despite its impact on mobility and functionality (12). When comes to women, this research is shown even more relevant as compared to men, they have lower levels of functionality and mobility $(13,14)$. Furthermore, the decline of those specified levels starts quickly from midlife. Based on this assumption, we hypothesized that TUG modified to asymptomatic adults is reliable and valid, and it can identify the decline of physical mobility through the age and correlate with FEC reviewed by ISWT. 


\section{Methods}

We conducted a cross-sectional observational study approved by the Ethics Committee in Research with Human Beings of the Federal University of São Paulo under number 1623/07 and according to the resolution 466/12 number of National Health Council.

Ninety-eight women from 40 to 84 years old were selected and divided into age groups, creating a nonpropabilistic sample of convenience. The strata were: 40-49 years $(n=24), 50-59$ years $(n=25), 60-69$ years $(n=26)$, and $\geq 70$ years $(n=23)$. From the sample, 58 participants were asked to compose a sub-sample, as described below.

Volunteers were recruited through social networks, the region's universities and local magazines. In order to get the sample of the present study, we excluded those participants who reported a previous medical diagnosis of heart disease, lung disease and/or musculoskeletal problems. After selection, the volunteers were informed about the procedures to be performed and then all participants signed a free and enlightening consent form.

\section{Clinical evaluation}

Before starting the evaluation, volunteers answered questions about previous health problems, medicine use and risk factors for cardiovascular disease development, such as age, family history, smoking, high blood pressure, dyslipidemia, diabetes, and obesity. Besides that, they answered to readiness activity questionary to physical activity (PAR-Q) $(15,16)$, to track possible contratindication to exercise risk stratification for cardiovascular events during the exercise was carried out according to the recommendation of the American College of Sports Medicine (17).

\section{Timed up and go test (TUG)}

TUG was performed using a standard armchair which has a support for the spine and arms, and a timer, according to that described by Podisiadlo \& Richardson (10). The test was performed in a flat course to $3 \mathrm{~m}$ walk in closed and covered place indoors.

We oriented the participants to support the back and arms, in the armchair, stand up, walk 3m, turn around, go back and sit down in the armchair again as soon as possible. The volunteers wore their usual footwear to perform the test. Each participant performed three tests, with 30s interval between them. The best time obtained from the three tests was considered performance score for this assessment.

The original test was slightly modified in this study. The only modification of the original TUF was the instruction to perform it "as soon as possible". We have chosen this procedure due to the presence of asymptomatic individuals in our sample.

Incremental shuttle walking test (ISWT)

ISWT (1) consists of walking path $10 \mathrm{~m}$, delimited by two cones, in progressive speed, which increases $0.17 \mathrm{~m} / \mathrm{s}$ every minute using a sound signal recorded on a $C D$, consisting of 12 stages of 1 minute each $(1020 \mathrm{~m})$. The original test was developed for patients with respiratory diseases, so we used the modified ISWT (6) to healthy. This test has 15 stages o fone minute each $(1500 \mathrm{~m})$, to prevent the "ceiling effect" that can occur during the test.

We oriented volunteers to increase their walking speed every minute until they were exausted. If they reached the cone before the sound signal, they should remain at the cone and wait for the next signal. The end of the test was determined by the interruption of the person in test, for any reason, or by the assessor when the participant could not keep the demanded speed to complete the course when the beep sounded (i.e., > 0,5 $\mathrm{m}$ to the closest cone).

During the test, we also observed the presence of low cardiac output symptoms such as dyspnea, severe pain, dizziness, cold sweats, cramps etc.

Before and after the test completion, we measured = heart rate, blood measure and psychophysiological sense of effort, through Borg scale. Each participant perfomed two tests, with a 30 minutes interval. Due to the incremental character, the distance in meters obtained in the second test was recorded and subjected to data analysis.

\section{Usual gait speed (UCS)}

We used the timed 10 meters walking test (5) to evaluate the spatial and temporal gait parameters we instruct the individuals to start walking. It was $1,2 \mathrm{~m}$ 
before the start of the route and end 1,2m after, in usual speed. Three consecutive tests were performed in an interval corridor. A stopwatch was used to measure performance. The average of three tests, in $\mathrm{m} / \mathrm{s}$, was subjected to data analysis.

\section{Berg balance scale (EEB)}

This test consists of performing 14 common tasks to everyday life. Each task can be scored from 0 to 4 and, in the total, the test reaches 56 in the score. The higher the score, He better the performance is, and consequently the greater the balance is. Each task is evaluated and scores through the examiner observation (18).

\section{Statistical analysis}

Participants were initially characterized by descriptive analysis. Data are presented as mean, standard deviation or median (interquartile range), according to the normal or non-normal distribution, respectively. As mentioned before, a subsample was created to verify the correlation between TUG and ISWT. Among the total participants, 58 (57 \pm 10 years) performed the walking test.

We used one-way analysis of variance (ANOVA), with post hoc Tukey test, to identify differences in the mean values of TUG between age groups. Then, we evaluate TUG reliability through intraclass correlation coefficient (ICC), and its confidence interval of 95\% (CI 95\%). In 58 participants, we evaluated the correlations between TUG, UGS, BBS and ISWT through Pearson's correlation coefficient. Finally, multiple stepwise linear regression was performed, to assess TUG's ability to predict FEC (i.e., ISWT). The probability of alpha error was set to $5 \%$.

The sample size was estimated based on the significant difference between groups (19). We considered $1^{\text {s }}$, as a significant difference in TUG runtime and $1.2 \mathrm{~s}$, as the variability. The effect magnitude standardized is 0.83 , resulting in approximately 26 participants in each group.

\section{Results}

Age, height, body mass, BMI, TUG performance, UGS and BBS of participants were presented as average and standard deviation (Table 1) and the subgroup which additionally held ISWT performed (Table 2).

Table 1 - Participants general features $(n=98)$

\begin{tabular}{lc}
\hline Variables & Mean \pm Standard Deviation \\
\hline Age (Years) & $57 \pm 10$ \\
Body Mass $(\mathrm{kg})$ & $67 \pm 12$ \\
Height $(\mathrm{cm})$ & $155.2 \pm 7$ \\
BMI $\left(\mathrm{kg} / \mathrm{m}^{2}\right)$ & $27.1 \pm 4$ \\
BTUG $(\mathrm{s})$ & $6.6 \pm 1,1$ \\
UGS $(\mathrm{m} / \mathrm{s})$ & $1.4 \pm 0.2$ \\
BBS & $54 \pm 2$ \\
\hline
\end{tabular}

Note: IMC = Body mass index; $B T U G=$ better timed up and go test; UGS = usual gait speed; $B B S=$ Berg balance scale.

Table 2 - Participants general feature who performed incremental shuttle walk test $(n=58)$

\begin{tabular}{lc}
\hline Variables & Mean \pm Standard Deviation \\
\hline Age (Years) & $57 \pm 10$ \\
Body Mass $(\mathrm{kg})$ & $69 \pm 13$ \\
Height $(\mathrm{cm})$ & $154.1 \pm 6$ \\
BMI $\left(\mathrm{kg} / \mathrm{m}^{2}\right)$ & $29.2 \pm 5$ \\
BTUG $(\mathrm{s})$ & $6.6 \pm 0.9$ \\
UGS $(\mathrm{m} / \mathrm{s})$ & $1.4 \pm 0.2$ \\
BBS & $54 \pm 2$ \\
ISWT $(\mathrm{m})$ & $412 \pm 84$ \\
\hline
\end{tabular}

Note: IMC = Body mass index; BTUG $=$ better timed up and go test; UGS = usual gait speed; BBS = Berg balance scale; ISWT = incremental shuttle walk test.

Participants with age $\geq 70$ showed worse TUG performance when compared to subgroups participants 40-49 and 50-59 years old. There was no significant difference related to participants from 60 to 69 years old (Figure 1). 


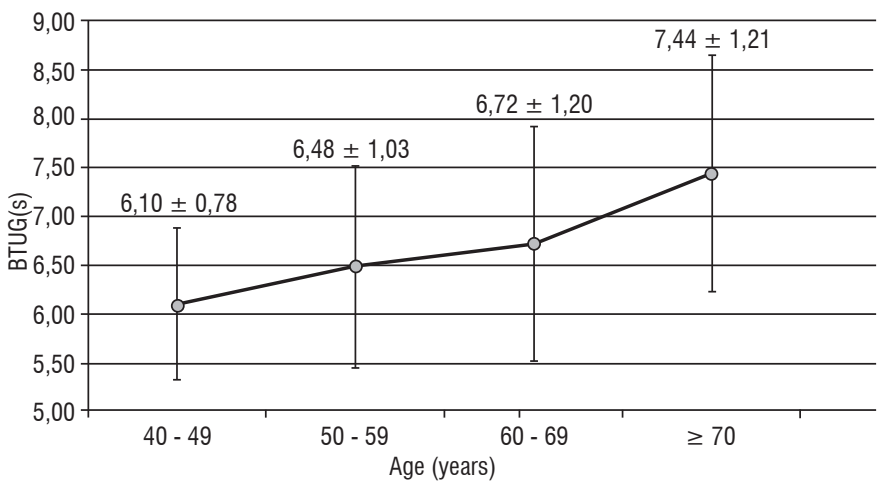

Figure 1 - Test performance "Timed up and go" stratified by age $(n=98)$.

Note: BTUG $=$ Better timed up and go test; ${ }^{\star} p<0.05: \geq 70$ vs. $40-49$ years old; $\# p<0.05: \geq 70$ vs. $50-59$ years old.

In the subgroup, TUG was significantly correlated $(\mathrm{p}<0,05)$ with ISWT $(\mathrm{r}=-0,72)$, UGS $(\mathrm{r}=-0,54)$ and BBS $(r=-0,58)$. Linear regression analysis showed TUG $\left(R^{2}=0,517\right)$ and $U G S\left(R^{2}=0,083\right)$ as determinants of FEC (Table 3).

Table 3 - Results of multiple regression analysis for prediction to covered distance on Incremental Shuttle Walk Test

\begin{tabular}{lccccl}
\hline \multicolumn{1}{c}{ Variable } & Coefficient & Standard Error & $\Delta \mathbf{R}^{2}$ & $\mathbf{R}^{2}$ & $\mathbf{P}$ \\
\hline Constant & 567.796 & 103.408 & - & - & - \\
TUG & -56.607 & 9.507 & 0.517 & 0.517 & 0.05 \\
UGS & 143.013 & 44.257 & 0.083 & 0.601 & 0.05 \\
\hline
\end{tabular}

Note:TUG = timed up and go test; UGS = usual gait speed; $\Delta R^{2}=$ partial determination coefficient; $R^{2}=$ total model determination coefficient.

ICC was excellent between the 1st and the 2nd TUG and between the 2nd and the 3rd (table 4).

Table 4 - Intraclass "timed up and go"

\begin{tabular}{cccc}
\hline & & \multicolumn{2}{c}{ Confidence Interval 95\% } \\
\cline { 3 - 4 } & & Lower Limit & Upper Limit \\
\hline TUG 1 X TUG 2 & 0.933 & 0.901 & 0.955 \\
TUG 2 X TUG 3 & 0.958 & 0.938 & 0.972 \\
\hline
\end{tabular}

Note: ICC = intraclass correlation coefitient; TUG1 $=1^{\circ}$ timed up and gote; TUG2 $=2^{\circ}$ timed up and go test; TUG3 $=$ teste timed up and go.

\section{Discussion}

In the present study, we verified that modified TUG can be useful to identify physical mobility decline through the age. Additionally, TUG showed significant correlations with UGS and with the balance, being able to predict FEC in non-institutionalized middle-aged women.

The reliability obtained in TUG test was excellent for the age group investigated. Our results were consistent with those reported for patients with chronic diseases (20 - 23). In 278 elderly patients with chronic heart failure, the ICC between TUG tests performed on two consecutive days was 0.93 (23). Despite the difference in test instruction, the result corresponded with our findings (23). Poncumhak et al. (22), found, among other field tests, excellent reliability (ICC 0.99 for running auxiliary device users and 1 without using running auxiliary device) of TUG to measure the independence of middle-aged patients with incomplete spinal Cord injury with and/or without a use of running auxiliary device. Similar to TUG, get up and go test also presented excellent interests reliability (ICC 0.98) for people with osteoarthritis (105 individuals -80 women around $62.9 \pm 9$ years old) (20). TUG was considered a reliable and effective for different sort of people, patients with chronic disease or mobility limitations, including middle-aged women. Thus, the test showed measures considered reproducible and clinical relevance for the studied sample.

We observed that participants performance in TUG decreased through aging. Participants between 40-49 and 50-59 years old showed much better performance than the ones around $\geq 70$. Similar results 
were observed in elderly from 60 years old $(7,10$, $19,24,25)$. Some factors, such as mobility and agility decline, as well as neuromuscular changes (26), expected with advancing age, may explain the increase in time o folder women in performing TUG. Our results were confirmed, the previous study showed that increasing the time taken to perform TUG starts at 50 years old, due to reduced muscle strength of hip extensors, quadríceps and ankle extensors (12). It would be related to the progression of decreased strenght which has different Standards for such muscle groups as well as individual aspects, taking the level of physical activity as an example $(12,27)$.

A meta-analysis that included 21 studies provided reference values about to the regular TUG test duration according to age. Thus, Bohannon (19) showed that individuals who spend more than 9 seconds, to 60-69 years old, 10.2 seconds to 70-79 years old, and 12.7 seconds to subjects at 80-99 years old, need some type of action related to muscle strength, balance, and/or mobility. Our sample is below those values in the strata 60-69 years old and $\geq 70$ years old, being out of classification suggested for intervention. This is probably due to the fact of being healthy women without difficulties. Nevertheless, the cited studies $(7,10,19,25,27,28)$ reinforce the relevance o four study, but, above all, the relationship between performance on TUG and the ability to perform physical exercise and activities of daily living $(8,27)$.

In literature, there are differences in methodology in performing TUG (19), in some studies was used the instruction to weak as quickly as provide and in others the recommendation was to perform safely test. The sample used in our study was also made up of middleaged adults ( $40 \mathrm{a} 64$ years old), the instruction to walk as quickly as possible may justify the performance difference among individuals at the same age between our study and the other mentioned studies $(7,10,19$, $24,25)$, once the performance of our participants was better. Despite the use of the modified test, we observed a decline in TUG performance with advancing age, as aforesaid. According to the previous study (28), TUG performed with such modification, may provide some additional information, as it is also related to executive function measures, which involves visuospatial and verbal information. According to the authors, the clinical relevance of this finding relates to the acceleration of functional decline and disability due to executive dysfunction (28), demonstrating one more utility that can be attributed to the use of this field test.
In our study, we also evaluated the correlation between TUG and FEC (i.e., ISWT) and obtained a significant negative correlation between the two of them, since the smaller the distance on the ISWT, the greater the time spent to perform TUG. In order to perform ISWT, the individual must more and change direction, requiring agility and balance to achieve it, as well as the TUG. Recent studies have shown ISWT correlation with balance $(3,4,29)$ and occurrence of falls (4). Our results showed that the lower the score of BBS, the greater the TUG runtime. According to McGough et al. (28), to run slower performance can be a compensatory strategy in an attempt to maintain the accuracy in performing daily activities. Thus, our results support findings from previous studies.

$\mathrm{Al}$ Haddad et al. (30) point out that TUG runtime also correlates inversely with the 6 - minute walk test (6WT) and it shows a sensitivity and specificity in relation to the history of falls in the previous year in patients with DPOC. Hwang et al. (23) suggest that $66 \%$ of the total variance of TUG in patients with chronic heart failure are due to the distance in 6WT and age. Thus, a better performance is associated with greater TUG distance in $6 \mathrm{WT}(23,24)$ and also to the fastest time in $10 \mathrm{~m}$ test (23), confirming our findings regarding the correlation between TUG and UGS.

Still relating to TUG and UGS correlation, Viccaro et al. (9) have suggested that both scores are useful especially when compared fastest performance of subjects with other considered intermediate and/or slower, so it was shown that the worsening of performance is associated with functional decline, even after adjusting for age and baseline function. Novaes et al. (5), have shown that there is a decline in UGS with increasing, wich was also consistent with the increased time required to perform TUG in our study. Thus would be related to reduced muscle strength and speed of contraction resulting from the aging, resulting in loss of mobility and therefore independence to perform daily activities (26).

Furthermore, these studies $(9,23,27,30)$ contribute to strengthening our argument for the use of field tests and their clinical relevance to detect damage to the mobility and functionality of individuals. We also emphasize that while reductions in muscle strength and functionality are simultaneous, as a result of the aging process, reduced functional capacity may be detected before, as suggested by Akbari e Mousavikhatir (12), and tests, such as the $10 \mathrm{~m}$ walking test, TUG 
and ISWT may be used to screen for the purpose of discriminating individuals at risk (9).

The limitations of this study should be considered. Our sample is only composed of women. Due to the low interest of males in the study, we chose to present only the female results. According to Gomes et al. (31), the demand for health services and health promotion initiatives is lower among men compared to women. The authors suggest that this behavior related to care still refers to the female gender, which may explain the lack of male volunteers in our study (31). Although our results can not be exceeded to men in this age group, the incidence of falls is higher in women (4). Therefore, our results are useful for the design of preventive strategies for middle-aged women and asymptomatic elderly.

The variables assessed in this study, such as mobility, balance and FEC are of upmost importance regarding the aging process, since the appearance of possible muscular strength deficits, functional capacity, and postural control lead to loss of independence and increase the number of risk factor for falls $(10,32$ - 34). Therefore, approaches to assist in the investigation of possible risk factors and changes resulting from the aging process, are clinically relevant for identifying functional impairment. As TUG, is a simple and quick test to perform, it may be useful to identify early mobility deficit in asymptomatic elderly and enables the development and implementation of preventive strategies of attention to health care of this population.

\section{Conclusion}

We conclude that the time of TUG is one of the determinants of FEC obtained in ISWT. In addition, TUG modified for middle-aged women and asymptomatic elderly is reliable and able to assess the decline of physical mobility with advancing age.

\section{References}

1. Singh SJ, Morgan MD, Scott S, Walters D, Hardman AE. Development of a shuttle walking test of disability in patients with chronic airways obstruction. Thorax. 1992;47(12):1019-24.
2. Singh SJ, Puhan MA, Andrianopoulos V, Hernandes NA, Mitchell KE, Hill CJ, et al. An official systematic review of the European Respiratory Society/American Thoracic Society: Measurement properties of field walking tests in chronic respiratory disease. Eur Respir J. 2014;44(6):1447-78.

3. Spagnuolo DL, Jürgensen $\mathrm{SP}$, Iwama $\mathrm{AM}$, Dourado $\mathrm{VZ}$. Walking for the assessment of balance in healthy subjects older than 40 years. Gerontology. 2010;56(5):467-73.

4. Bardin MG, Dourado VZ. Association between the occurrence of falls and the performance on the Incremental Shuttle Walk Test in elderly women. Rev Bras Fisioter. 2012;16(4):275-80.

5. Novaes RD, Miranda AS, Dourado VZ. Usual gait speed assessment in middle-aged and elderly Brazilian subjects. Rev Bras Fisioter. 2011;15(2):117-22.

6. Dourado VZ, Guerra RLF, Tanni SE, Antunes LCO, Godoy I. Valores de referência para o teste de caminhada com carga progressiva em indivíduos saudáveis: da distância percorrida às respostas fisiológicas. J Bras Pneumol. 2013;39(2):190-7.

7. Steffen TM, Hacker TA, Mollinger L. Age- and genderrelated test performance in community-dwelling elderly people: Six-Minute Walk Test, Berg Balance Scale, Timed Up \& Go Test, and gait speeds. Phys Ther. 2002;82(2):128-37.

8. Wennie Huang WN, Perera S, VanSwearingen J, Studenski S. Performance measures predict onset of activity of daily living difficulty in community-dwelling older adults. J Am Geriatr Soc. 2010;58(5):844-52.

9. Viccaro LJ, Perera S, Studenski SA. Is timed up and go better than gait speed in predicting health, function, and falls in older adults? J Am Geriatr Soc. 2011;59(5):887-92.

10. Podsiadlo D, Richardson S. The timed "Up \& Go": a test of basic functional mobility for frail elderly persons. J Am Geriatr Soc. 1991;39(2):142-8.

11. Shimada H, Tiedemann A, Lord SR, Suzukawa M, Makizako H, Kobayashi K, et al. Physical factors underlying the association between lower walking performance and falls in older people: a structural equation model. Arch Gerontol Geriatr. 2011;53(2):131-4. 
12. Akbari M, Mousavikhatir R. Changes in the muscle strength and functional performance of healthy women with aging. Med J Islam Repub Iran. 2012;26(3):125-31.

13. Samson MM, Meeuwsen IB, Crowe A, Dessens JA, Duursma SA, Verhaar HJ. Relationships between physical performance measures, age, height and body weight in healthy adults. Age Ageing. 2000;29(3):235-42.

14. Kuh D, Bassey EJ, Butterworth S, Hardy R, Wadsworth MEJ, Musculoskeletal Study Team. Grip strength, postural control, and functional leg power in a representative cohort of British men and women: associations with physical activity, health status, and socioeconomic conditions. J Gerontol A Biol Sci Med Sci. 2005;60(2):224-31.

15. Thomas S, Reading J, Shephard RJ. Revision of the Physical Activity Readiness Questionnaire (PAR-Q). Can J Sport Sci. 1992;17(4):338-45.

16. Matsudo S, Araújo T, Marsudo V, Andrade D, Andrade E, Oliveira LC, et al. Questinário internacional de atividade f1sica(IPAQ): estudo de validade e reprodutibilidade no Brasil. Rev Bras Ativ Fis Saude. 2001;6(2):5-18.

17. Garber CE, Blissmer B, Deschenes MR, Franklin BA, Lamonte MJ, Lee IM, et al. American College of Sports Medicine position stand. Quantity and quality of exercise for developing and maintaining cardiorespiratory, musculoskeletal, and neuromotor fitness in apparently healthy adults: guidance for prescribing exercise. Med Sci Sports Exerc. 2011;43(7):1334-59.

18. Berg KO, Maki BE, Williams JI, Holliday PJ, WoodDauphinee SL. Clinical and laboratory measures of postural balance in an elderly population. Arch Phys Med Rehabil. 1992;73(11):1073-80.

19. Bohannon RW. Reference values for the timed up and go test: a descriptive meta-analysis. J Geriatr Phys Ther. 2006;29(2):64-8.

20. Piva SR, Fitzgerald GK, Irrgang JJ, Bouzubar F, Starz TW. Get up and go test in patients with knee osteoarthritis. Arch Phys Med Rehabil. 2004;85(2):284-9.

21. Botolfsen P, Helbostad JL, Moe-nilssen R, Wall JC. Reliability and concurrent validity of the Expanded Timed Up-and-Go test in older people with impaired mobility. Physiother Res Int. 2008;13(2):94-106.
22. Poncumhak P, Saengsuwan J, Kamruecha W, Amatachaya S. Reliability and validity of three functional tests in ambulatory patients with spinal cord injury. Spinal Cord. 2013;51(3):214-7.

23. Hwang R, Morris NR, Mandrusiak A, Mudge A, Suna J, Adsett J, et al. Timed Up and Go Test: A Reliable and Valid Test in Patients With Chronic Heart Failure. J Card Fail. 2016;22(8):646-50.

24. Shumway-Cook A, Brauer S, Woollacott M. Predicting the probability for falls in community-dwelling older adults using the Timed Up \& Go Test. Phys Ther. 2000;80(9):896-903.

25. Isles RC, Choy NLL, Steer M, Nitz JC. Normal values of balance tests in women aged 20-80. J Am Geriatr Soc. 2004;52(8):1367-72.

26. Raj IS, Bird SR, Shield AJ. Aging and the forcevelocity relationship of muscles. Exp Gerontol. 2010;45(2):81-90.

27. Allison LK, Painter JA, Emory A, Whitehurst P, Raby A. Participation restriction, not fear of falling, predicts actual balance and mobility abilities in rural community-dwelling older adults. J Geriatr Phys Ther. 2013;36(1):13-23.

28. McGough EL, Kelly VE, Logsdon RG, McCurry SM, Cochrane BB, Engel JM, et al. Associations between physical performance and executive function in older adults with mild cognitive impairment: gait speed and the timed \&quot;up \&amp; go\&quot; test. Phys Ther. 2011;91(8):1198-207.

29. Hayashi D, Gonçalves CG, Parreira RB, Fernandes KBP, Teixeira DC, Silva RA, et al. Postural balance and physical activity in daily life (PADL) in physically independent older adults with different levels of aerobic exercise capacity. Arch Gerontol Geriatr. 2012;55(2):480-5.

30. Al Haddad MA, John M, Hussain S, Bolton CE. Role of the Timed Up and Go Test in Patients With Chronic Obstructive Pulmonary Disease. J Cardiopulm Rehabil Prev. 2016;36(1):49-55.

31. Gomes R, Nascimento EF, Araújo FC. Por que os homens buscam menos os serviços de saúde do que as mulheres? As explicações de homens com baixa escolaridade e homens com ensino superior. Cad Saude Publica. 2007;23(3):565-74. 
32. Tinetti ME. Clinical practice. Preventing falls in elderly persons. N Engl J Med. 2003;348(1):42-9.

33. Thrane G, Joakimsen RM, Thornquist E. The association between timed up and go test and history of falls: the Tromsø study. BMC Geriatr. 2007;7:1.
34. Williams JS, Ng N, Peltzer K, Yawson A, Biritwum R, Maximova T, et al. Risk factors and disability associated with low back pain in older adults in low- and middle-income countries. Results from the WHO study on global AGEing and adult health (SAGE). PLoS One. 2015;10(6): e0127880.

Received in 03/06/2016

Recebido em 06/03/2016

Approved in 08/18/2016

Aprovado em 18/08/2016 
